\title{
Unmanned Aerial Vehicle (UAV) for Parcel Delivery
}

\author{
Neha Gupta ${ }^{1}$ \\ Department of Information Technology(IT), \\ JSS Academy of Technical Education \\ (JSSATE), Noida, India,
}

ORCID: 0000-0003-4288-4521

\author{
Rosey Chauhan ${ }^{2}$ \\ Department of IT, \\ JSSATE, Noida, India,
}

\author{
Shikha Chadha ${ }^{3}$ \\ Department of IT, \\ JSSATE, Noida, India,
}

\begin{abstract}
Air Drones, Unmanned Aerial Vehicles (UAV), autonomous or tele-operated flying machines are the aircrafts that doesn't require a human onboard for controlling it. They can be managed manually by a remote wireless operator or automatically using the software. Our purpose in this paper is to present the use of drones for parcels and small packages delivery that can be used commercially or in emergency situations. A drone that is capable of lifting weights up to $1-$ $1.5 \mathrm{~kg}$, an autonomous system that would control the drone completely using the Raspberry $\mathrm{Pi}$ a microprocessor that will connect the drone to the control system and will control the drone throughout the process. A Global Positioning System (GPS) that helps the drone to reach its destination and return to the base station. This paper presents how drones would be helpful in delivering small packages helping ecommerce expand their business, and also can used to deliver in emergency situations like deliveries of blood, medicinal goods and many other items that a person or professional can use in emergency, which takes lot of time currently for a person to deliver by hand.
\end{abstract}

Keywords:UAV, Rasberry Pi, GPS

\section{INTRODUCTION}

Air drones are being used in the military operations for survey and defense purposes under the control of a country's government[1]. Other areas where drones find its application are in the surveys of agriculture land which is also a government initiative to optimize efficiency. And other is the use of drones for filming and cinematography in movies, sports, social events and functions. Other areas where drones are being used and in accordance to the government permission is usage in closed warehouses and manufacturing units. But drones haven't been used in commercial applications where it could benefit the people living in society and is helpful in daily lives.

Through this paper we intend to use the drones for delivery for various packages that can be used to deliver variety of items. As drones haven't been used to deliver packages and using drones would make the delivery process faster, autonomous and would require less resources and man power[2]. The requirements for this are, a drone that is capable of lifting weights up to $1-1.5 \mathrm{~kg}$, an autonomous system that control the drones completely and other components to make it capable for delivering the package.

\section{RELATED WORK}

[3] conducted a feasibility analysis of associated cost of, "Andreas Raptopoulos on physical transport". Assumptions that were made for the analysis are:

a) Around $2 \mathrm{~kg}$ of Payload.

b) $10 \mathrm{~km}$ of range

c)Wind current of approx. $30 \mathrm{~km} / \mathrm{h}$.

Energy usage in $\mathrm{kW}$ can be approximated

$$
\frac{\left(m_{p}+m_{v}\right) v}{370 \eta r}+p
$$

where

$m_{p} \quad$ denotes payload mass $(\mathrm{kg})$

$m_{v} \quad$ denotes vehicle mass $(\mathrm{kg})$

$r$ denotes lift-to-drag ratio;

$\eta$ denotespower transfer efficiency for motor and propeller;

$p \quad$ denotes power consumption of electronics, in $\mathrm{kW}$;

$v \quad$ denotes cruising velocity, in $\mathrm{km} / \mathrm{h}$.

The worst-case energy demand in $\mathrm{kWh}$ can be approximated.

$$
\frac{d}{1-v}\left(\frac{m_{p}+m_{v}}{370 \eta r}+\frac{p}{v}\right)
$$

where

$d \quad$ denotes maximum range $(\mathrm{km})$;

$v \quad$ denotes ratio headwind to airspeed;

The total cost of electricity per km can be approximated.

$$
\frac{k}{l}\left(\frac{m_{p}+m_{v}}{370 \eta r}+\frac{p}{v}\right)
$$

where

c denotes cost of electricity, in $\$ / \mathrm{kWh}$;

e denotes charging efficiency; 
International Journal of Engineering Research and Technology. ISSN 0974-3154, Volume 13, Number 10 (2020), pp. 2824-2830

(C) International Research Publication House. http://www.irphouse.com

Assumptions made:

Cost of Electricity

\section{$0.1 \$ / \mathrm{kW} \mathrm{h}$}

Charging Efficiency

The above assumptions revenues to a cost of around 0.2 cents per $\mathrm{km}$ for a payload of $2 \mathrm{~kg}$.

[4] discussed about the mechanics of flight control of drones. Quadcopter is also known as quadrotor and is a four rotor helicopter with electronic sensors and control systems.

Drones have been used for the past 2 decades in military or only government organizations due to security reasons but in the last 2-3 years commercial organizations like Amazon, FEDEX etc. want to use UAV for their parcel delivery for faster delivery and at a very lost cost. Given below are the details of the work done on UAV for using them in parcel delivery.

1. Amazon Prime Air [5\&6]: With the latest drone-based delivery program, the amazon's aim is to use drones for delivering packages to their customers in half hour or less. Developers say that the drones are capable of flying within a specified range of about 10 mile, and can carry item having an average weight of around 5 pounds. Although though this project is still in development stage, Amazon is optimistic that they will launch this method of distribution very soon in the near future.

2. Domino's [7]: The internationally renowed Domino's Pizza, more specifically their UK division, has announced that they are planning of using drones for the pizza delivery.

Demicopter's will be used to deliver pizza's to the customer and a video of this demo has been released. This idea is being considered by many other food delivering companies and will definitely provide a boom to the industry.

3. FEDEX: The popular package delivery company is also considering introducing the drone technology for the improvement of their facilities and services provided to the customers.Fedex plans to use delivery vehicles (trucks) as the drone base which help in takeoff and landing of drones on the roof.

\section{MATERIAL \& METHODS}

\section{A. Materials}

a.) A drone that is capable of lifting weight of up to $0.5 \mathrm{~kg}$.

b.) To reduce the resources currently being used to deliver the products to the consumer and along with that a faster delivery in a small vicinity of area covering about $4 \mathrm{~km}$ of circular area from a base station.

c.) Reduce the cost of delivering a parcel comparatively than what is being used in man powered delivery system.

d.) Using new and advanced technology to reduce the workload in human power and less consumption of natural resources.
Detailed analysis of the hardware components and their specifications is presented in this section. Along with that the connections that are to be made in order to make the system work is also presented.

\section{B. Hardware}

i.) Frame Model: S500 Quadcopter Frame High Landing Gear

\section{Specifications:}

1. Frame Weight: 405gm

2. Wheelbase: $500 \mathrm{~mm}$

3. Motor Mounting Hole Diameter: $3 \mathrm{~mm}$

4. Landing Gear Material: ABS

5. Arm Size: 220 x $40 \mathrm{~mm}$.

6. Landing Gear Length: 200mm

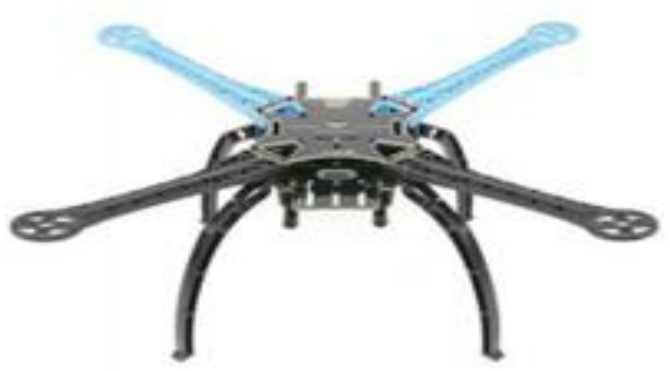

Figure 1. S500 Frame

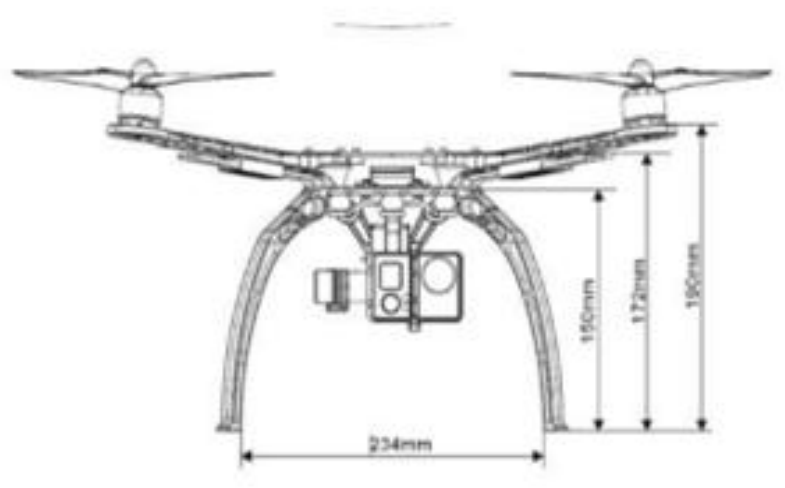

Figure 2. S500 Frame Dimensions

ii.) Motors

Model: EMAX XA2212 980KV Outrunner Brushless DC Motor

Specifications:

1. Motor KV (RPM/V): 980

2. Maximum Thrust: $880 \mathrm{gm}$ 
3. Framework: 12N14P

4. Shaft Diameter (mm): 3

5. LiPo Batteries: $2 \mathrm{~S}-3 \mathrm{~S}$

6. Propellers: 9 - 10 inches

7. Length (mm): 43.16

8. Width (mm): 27.9

9. Weight (mm): 55

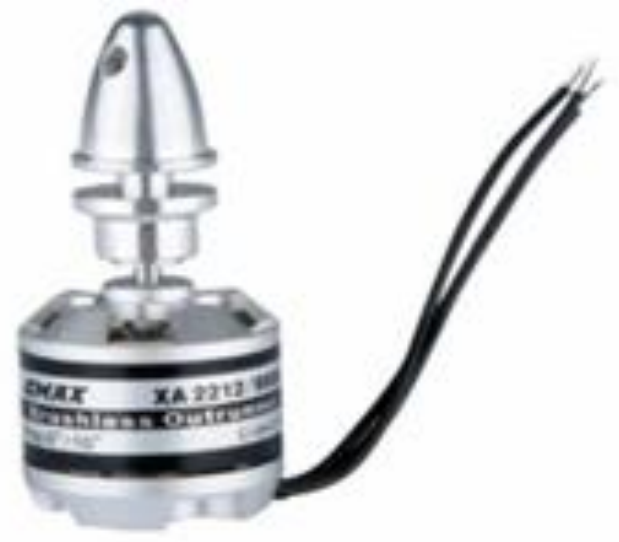

Figure 3. EMAX XA2212 Motor

iii.) Propellers Model: Propellers 1045(10X4.5) Carbon Nylon

Specifications:

1. Material: Carbon Nylon

2. Color: Black

3. No. of Blades: 2

4. Length (inch): 10

5. Pitch (inch): 4.5

6. Shaft Diameter (mm): 9.5

7. Total Length (mm): 254

8. Plastic Reducers: 3, 3.17, 4, 5, 6, 8

9. Weight (gm): 32

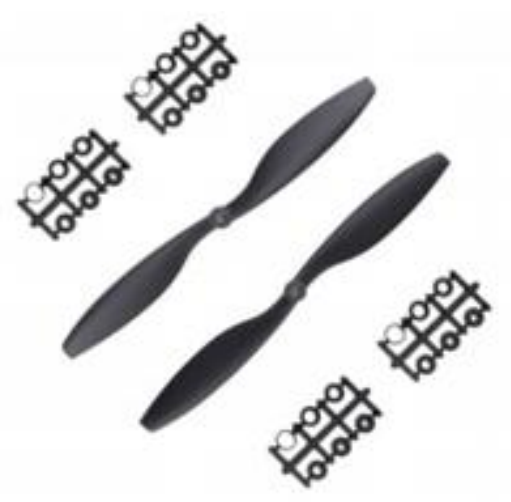

Figure 4. 1045(10X4.5) Carbon Nylon Propellers

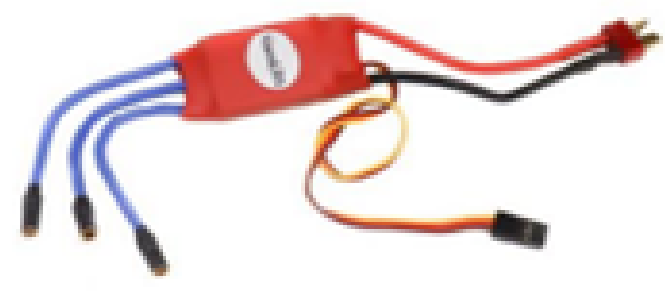

Figure 5. 30A BLDC ESC Electronic Speed Controller

iv.) Battery Model: Lithium polymer (LiPo) 3S 30C/60C 3000mAh battery pack

Specifications:

1. Capacity :3000 mAh

2. Weight : $215 \mathrm{gm}$

3. Output Voltage:11.1Volts

4. Charge Rate: 1-3C

5. Discharge-Plug: XT 60

6. Balance-Plug: JST XH

7. Length in $\mathrm{mm}: 136$

8. Width in $\mathrm{mm}: 43$

9. Height in $\mathrm{mm}: 17$

10. Maximum Burst Discharge: 90.0A (30c)

11. Maximum Charge Rate: ' $5 \mathrm{C}$ '

12. Maximum Continuous Discharge: 180.0A (60C)

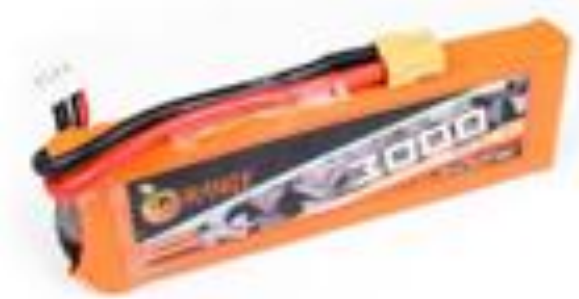

Figure 6. 3000mAh3S 30C/60C Lithium polymer battery pack (LiPo)

v.) Radio Controller (RC)

Model: FS-i6FlySky with 6CH2.4G PPM RC Transmitter and a FS-iA6B Receiver

Specifications:

TRANSMITTERFS-i6:

1. Model Type: Airplane /Heli/Glider

2. Band Type: 142

3. System2.4ghz:AFHDS\&AFHDS 2A 
International Journal of Engineering Research and Technology. ISSN 0974-3154, Volume 13, Number 10 (2020), pp. 2824-2830 (C) International Research Publication House. http://www.irphouse.com

\section{Code : GFSK}

5. Port DSC: PS2

6. Output: PPM

7. Charger Port: NA

8. ANT length in mm: $26 * 2$ (two antenna)

9. On-line update: Required

10. Certificate: FCC, CE0678

11. Model Memories: 20

12. Channel Order:CH-1 Aileron, CH-2 Elevator, CH-3 Throttle, CH-4 Rudder, Ch 5 \& 6

vi.) FS-iA6B Receiver:

1. Channel No. : 6 .

2. Range of Frequency: 2.4055 to $2.475 \mathrm{GHz}$.

3. Band Width No. : 140

4. Transmitting Power in $\mathrm{dBm}: \leq 20$

5. RF Receiver Sensitivity in $\mathrm{dBm}: 105$

6. 2.4G Mode: The second iteration of the upgraded variant of the automated adaptive FM system.

\section{Encoding: GFSK.}

8. Antenna Length in mm: 2 x 26 (two antenna).

9. Input Power: 4.0 to 8.4 VDC (2A).

10. Dimension in mm: $47 \times 26.2 \times 15$

11. Weight in gm: 14.9

12. Data Acquisition Interface: Required

13. Model Type: Helicopter/ Glider/ Airplane

Compatible Transmitter:

Compatible with FS-GT2E, FS-GT2GFS-i4, FS-i6

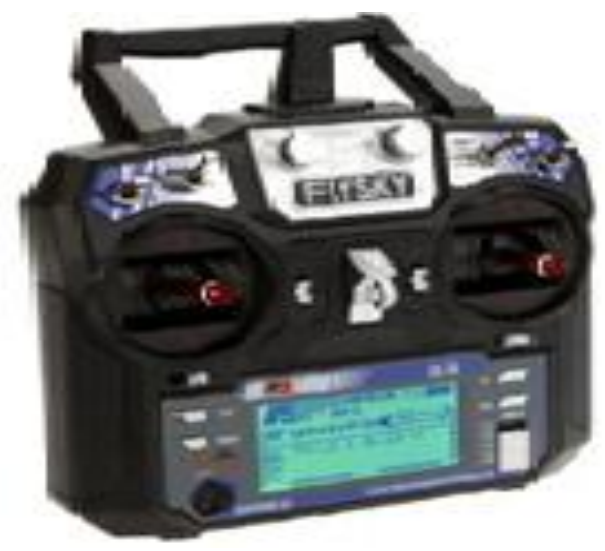

Figure 7.Flysky FS-i6 2.4G 6CH PPM RC Transmitter

\section{vii.) Flight Controller}

Model:32 Bit Autopilot Pixhawk 2.4.8 Drone Flight Controller PX4

Specifications:

1. Processor:

- $\quad$ STM32F427 Cortex M4 core 32 bit with FPU.

- Co-Processor : 32-bit STM32F103 failsafe

- $168 \mathrm{MHz}$

- RAM $128 \mathrm{~KB}$

2. Sensors:

- 16-bitST Micro L3GD20H gyroscope.

- ST Micro X4HBA 303H 14-bit accelerometer/magnetometer.

- 3-axis accelerometer/gyroscope Inverse MPU 6000.

- Barometer MEAS MS5607.

3. Interfaces:

- 2x with HW flow control ,1 high power capable, $5 x$ UART (serial ports)

- 2x CAN (1 with an internal 3.3V transceiver, one on expansion connector).

- DSM2 /Spektrum DSM / DSM-X® Satellite compatible input.

- Futaba S.BUS® compatible output and input.

- $\quad$ PPM sum signal input.

- $\quad$ RSSI input(PWM or voltage).

- $\mathrm{I} 2 \mathrm{C}$.

- $\quad 6.6 \mathrm{~V} \&$ SPI ADC inputs.

- $\quad$ External micro USB port extension \& Internal micro USB port.

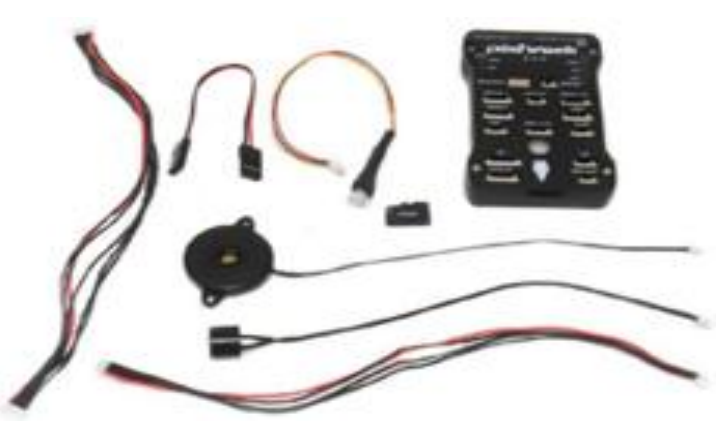

Figure 8.Pixhawk 2.4.8 Drone Flight Controller 
International Journal of Engineering Research and Technology. ISSN 0974-3154, Volume 13, Number 10 (2020), pp. 2824-2830

(C) International Research Publication House. http://www.irphouse.com

\section{viii.) Microprocessor}

Model: Raspberry Pi 3 64bit CPU Broadcom BCM2837Model B Quad Core $1.2 \mathrm{GHz}$

\section{Specifications:}

\section{RAM 1GB}

2. Bluetooth Low Energy (BLE) \&BCM43438 wireless LAN on board

3. Ethernet 100 Base

4. Extended GPIO40-pin

5. 40-pin 4 USB

6. Composite video port\& 4 Pole stereo output

7. HDMI Full size

8. CSI camera port (for connecting a Raspberry Pi camera)

9. DSI display port (for connecting a Raspberry Pi touch) screen display

10. Micro SD port (for loading your operating system and storing data)

11. Upgraded switched Micro USB power (source up to $2.5 \mathrm{~A})$

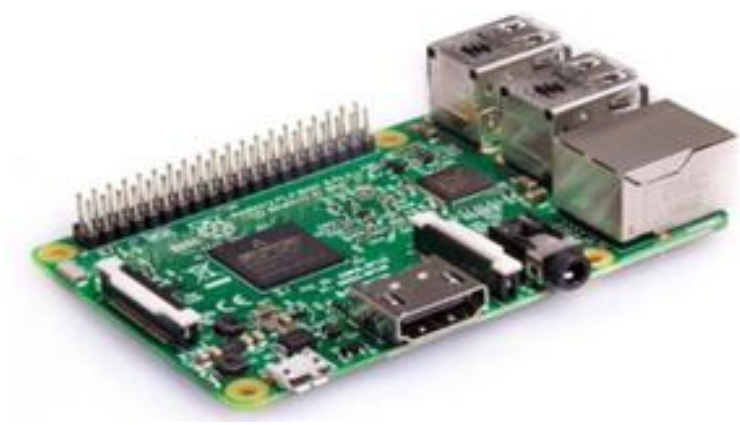

Figure 9. Raspberry Pi 3 Model B

ix.) GPS (Global Positioning System) [7]

Model: NEO-M8N GPS (with Compass)

Specifications:

1. Receiver-Type: Ublox M8 Engine 72 Channel

2. Main-Chip: Ublox NEO-M8N

3. Supply Voltage: $0.5 \sim 3.6$

4. Sensitivity: Tracking and Navigation (in $\mathrm{dBm}$ ): 161

5. Position Accuracy: Autonomous: $2.5 \mathrm{~m}$, SBAS: $2.0 \mathrm{~m}$

6. Navigation Update Rate: Max. Up to $18 \mathrm{~Hz}$

7. Operating Temperature Range: From $-45 \mathrm{C}$ to $105 \mathrm{C}$

8. Tracking Sensitivity in $\mathrm{dBm}:-161$

9. Co-Ordinate System: WGS-84

10. Capture Time: 0.1s (Average)
11. Cold Start Time (in seconds): 30

12. Warm Start Time (in Seconds): 1

13. Boot Time (in Seconds): 1

14. Max. Altitude: 18000

16. Dimensions LxWxH (in mm) : 54 x 22 (Dia. x W)

17. Weight (in gm): 23

18. Cable Length (in $\mathrm{cm}$ ): 20

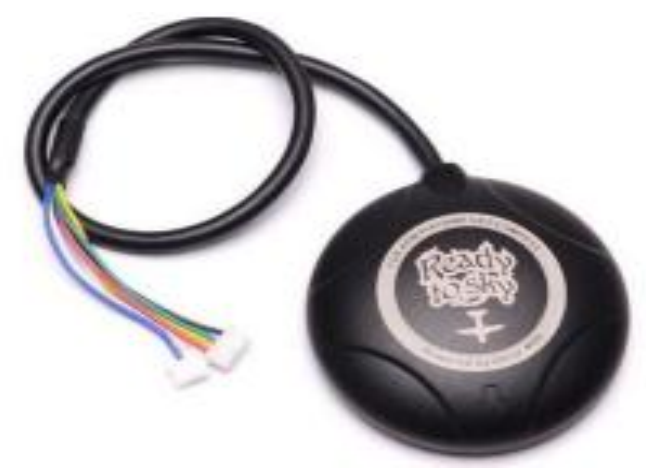

Figure 10. NEO-M8N GPS with Compass

\section{METHODOLOGY}

The proposed system is capable of lifting the weight of upto $1 \mathrm{~kg}$. It will control the drone actions and function including the pickup, drop of the package and the navigation. Therefore, the steps of the developed system are-

i.) To receive the coordinates of the drop location of the package.

ii.) To determine the shortest path predictable for the drone to enter the final location and return to the root station.

iii.) To find all the routes and navigation would be controlled using the GPS.

iv.) To develop a system using camera/s and lasers for finding any obstruction in the path of the drone and how to handle it and go around or over it whichever may be the possible and most efficient way.

v.) To develop a system for security which would verify the customer to deliver the item.

\section{RESULTS \& DISCUSSIONS}

a.) As for the successful completion of the delivery the system would be starting from $100-200$ gm of payload and gradually increasing the capacity of the drone to at most $1 \mathrm{~kg}$ of weight for better efficiency.

b.) A range of about $4 \mathrm{~km}$ from the base station to drop off point with wind current of up to $30 \mathrm{~km} / \mathrm{h}$ so that a delivery could be completed in one full single charge covering a distance of at most $10 \mathrm{kms}$ in a single round trip, giving us an extra $2 \mathrm{~km}$ of distance travel in case of any emergency. 
c.) With all the calculations done including the air speed of up to $45 \mathrm{~km} / \mathrm{h}$, headwinds of up to $30 \mathrm{~km} / \mathrm{h}$, electricity consumption, air drag, lift, drag and other operations that would be required during the operation, the cost for delivery of the package of at most $1 \mathrm{~kg}$ package would be less than Rs. 15, which is way more efficient than what is being used right now.

\section{CONCLUSION \& FUTURE WORK}

The quadcopter on completion and after initializing the setup the drone is ready to deliver the parcel. All we need to add the hinge system under the drone for parcel placement. The flight controller initialize the drone motors and the microprocessor Raspberry Pi 3 uses the wireless connection and provide the destination and source co-ordinates to the flight controller. The GPS helps in finding the destination co-ordinates, and providing the details to the flight controller and system uses the Ardupilot software along with the flight controller, so the quadcopter reaches its destination. The motors thrust, yaw and pitch are controlled by the flight controller with the configuration set by the software Ardupilot, and the data is sent by the Ardupilot to the microprocessor Raspberry Pi, installed in the quadcopter, which drives the drone and its motor to reach its destination. As mentioned, delivery through UAV's is very economic and resource saving. The cost of delivering the parcel using a UAV is just ₹ 3 per $\mathrm{km}$ for the drone flight. And for a radius of $4 \mathrm{~km}$ of the delivery area, a drone would fly a maximum of $8 \mathrm{~km}$ in a round trip which cost to ₹ 24 for one delivery, which is very economic considering the manual power, travelling sources and other factors that are required in delivering a parcel through normal means using human forces.

\section{REFERENCES}

[1] S. Aldhaher, P. D. Mitcheson, J. M. Arteaga, G. Kkelis, and D. C. Yates, "Light-weight wireless power transfer for mid-air charging of drones," 2017 11th Eur. Conf. Antennas Propagation, EUCAP 2017, pp. 336-340, 2017, doi: 10.23919/EuCAP.2017.7928799.

[2] P. Wing, “Air Traffic Control for Delivery Drones," pp. 32-33,

[3] D’Andrea R., “Can Drones Deliver", IEEE Transactions on Automation Science and Engineering, Vol. 11, NO. 3, JULY 2014.

[4] Ukey A., Agarwal A., Wadekar D., Godara H., Banker J., Sholapurkar M., Sinha T., "Quadcopter Dynamics", B. Tech Report, Digital Course Project, IIT Bombay, 2011.

[5] "Amazon Prime Air: Amazon new delivery system.", https://www.amazon.com/Amazon-

PrimeAir/b?ie $=$ UTF8\&node $=8037720011$

[6] S. M. Shavarani, M. G. Nejad, F. Rismanchian, and G. Izbirak, "Application of hierarchical facility location problem for optimization of a drone delivery system: a case study of Amazon prime air in the city of San Francisco," Int. J. Adv. Manuf. Technol., vol. 95, no. 912, pp. 3141-3153, 2018, doi: 10.1007/s00170-0171363-1.

[7] J. Hwang, S. B. Cho, and W. Kim, "Consequences of psychological benefits of using eco-friendly services in the context of drone food delivery services," J. Travel Tour. Mark, vol. 36, no. 7, pp. 835-846, 2019, doi: 10.1080/10548408.2019.1586619.

[8] S. N. Zenk, S. A. Matthews, A. N. Kraft, and K. K. Jones, "How many days of global positioning system (GPS) monitoring do you need to measure activity space environments in health research?," Heal. Place, vol. 51, no. January, pp. 52-60, 2018, doi: 10.1016/j.healthplace.2018.02.004.

[9] Bamburry D., "Drones: Designed for product delivery.”, DMI Spring, 2015.

[10] Eatemadi M., "Mathematical Dynamics, Kinematics Modeling and PID Equation Controller of Quadcopter" International Journal of Applied Operational Research, Vol. 7, No. 1, pp. 75-85, Winter 2017

[11] Halliday B., "Drones: Mastering Flight Techniques.", Two Cats Publishing, 2017.

[12] Juniper A., "The Complete Guide to Drones". Hachette: $\mathrm{UK}, 2015$.

[13] Kim S., Moon I., "Travelling Salesman Problem with a drone station", IEEE Transactions on Systems, Man, And Cybernetics: Systems”, Vol. 49, Issue: 1, Jan 2019.

[14] Murray C. C., Chu A. G., "The flying sidekick traveling salesman problem: Optimization of drone assisted parcel delivery", Transportation Research Part C: Emerging Technologies, Elsevier, Vol 54, pp 86-109, 2015.

[15] Vidyanathan V., "What is Drone Technology?", 9 March 2019, https://www.scienceabc.com/innovation/what-is-dronetechnology.html

[16] Yakimenko O., "Using Multirotor Drones in Engineering of Systems Curricula", Workshop on Research, Education and Development of Unmanned Aerial Systems (REDUAS), Linköping, Sweden, October 3-5, 2017.

[17] Drone Nodes, "HOW TO BUILD A DRONE | STEP BY STEP GUIDE", https://dronenodes.com/how-tobuild-a-drone/ [13]Caleberg, Drone DOJO, "How to build a Drone | A DIY Guide", https://dojofordrones.com/build-adrone.

[18] M. Hassanalian and A. Abdelkefi, "Classifications, applications, and design challenges of drones: A review," Prog. Aerosp. Sci., vol. 91, no. November 2016, pp. 99-131, 2017, doi: 10.1016/j.paerosci.2017.04.003.

[19] S. Aldhaher, P. D. Mitcheson, J. M. Arteaga, G. Kkelis, 
International Journal of Engineering Research and Technology. ISSN 0974-3154, Volume 13, Number 10 (2020), pp. 2824-2830 (C) International Research Publication House. http://www.irphouse.com

and D. C. Yates, "Light-weight wireless power transfer for mid-air charging of drones," 2017 11th Eur. Conf. Antennas Propagation, EUCAP 2017, pp. 336-340, 2017, doi: 10.23919/EuCAP.2017.7928799.

[20] J. Hwang, S. B. Cho, and W. Kim, "Consequences of psychological benefits of using eco-friendly services in the context of drone food delivery services," J. Travel Tour. Mark., vol. 36, no. 7, pp. 835-846, 2019, doi: 10.1080/10548408.2019.15866 